\title{
Squamous Cell Abnormalities and Risk Factors on 10,979 Pap-Smears in a Tertiary Care Hospital in Trivandrum, South India
} \author{
Thiruvananthapuram, Kerala, INDIA \\ *Address for Correspondence: \\ Dr. Kalavathy MC \\ Assistant Professor \\ Division of Cancer Epidemiology \& Bio-Statistics \\ Regional Cancer Centre \\ Trivandrum- 695 011, Kerala, India \\ *E-mail: kochettankunjukuttu[at]gmail.com
}

Kalavathy $\mathrm{MC}^{1}$, Aleyamma Mathew ${ }^{1}$, Sujathan $\mathrm{K}^{2}$, Saritha $\mathrm{VN}^{2}$, Jagathnath Krishna KM ${ }^{1}$, Jayasree $\mathrm{K}^{3}$

${ }^{1}$ Division of Cancer Epidemiology \& Bio-statistics, ${ }^{2}$ Division of Cancer Research, ${ }^{3}$ Division of Pathology, Regional Cancer Centre,

\begin{abstract}
The study aims at assessing squamous abnormalities and risk factors among women visited a tertiary care hospital for gynaecological problems in Trivandrum, south India. Regional Cancer Centre (RCC), Trivandrum, has been conducting a clinic in Women \& Children Hospital, Trivandrum, since 2006, where women attended for gynaec problems were referred to routine Pap-smear. Age and reproductive factors were collected. The processing of the smear was done at RCC. Logistic regression analysis was employed to assess the odds ratio (OR) and 95\% confidence interval (CI). 10,979women had undergone Pap-smear during 2010-2015. Among these, atypical squamous cells of unspecified significance were $2.9 \%$, low grade squamous intra-epithelial lesions, high-grade squamous intraepithelial lesions (HSIL)/cancers were 1.6\%. For developing HSIL/cancers women with higher education had OR of 0.20 (CI: 0.07-0.58) compared to women with no education. Women with age at marriage $>30$ years had OR of 0.23 (CI: 0.08-0.66) for developing HSIL/cancer compared to women with age at marriage <20 years. Women with unhealthy cervix had OR of 3.16 (CI: 1.80-5.54) for having HISL/cancer compared to women with normal cervix. In conclusion, Pap-smear clinics would help to detect women in premalignant conditions and also has a greater role in the diagnosis of inflammatory lesions.
\end{abstract}

Keywords: Pap-smear, ASCUS, Squamous Intraepithelial Lesions, LSIL, HSIL

\section{Introduction}

Incidence and mortality due to cervix uteri cancer have been declined considerably during the past 40 years [1]. The decline has been attributed to a combination of factors, including improved genital hygiene and treatment modalities and the beneficial effects of organized population-based cytological screening programmes. Although, incidence of this disease has been decreasing, it is still the second most common cancer among women in most of the developing countries and thus it remains a major health problem [2]. Around 123,000 new cervix utericancers and of which 67,000 deaths occur annually in India, accounting to nearly $1 / 3^{\text {rd }}$ of the global deaths due to this disease [1].

Cervix uteri cancer is a readily preventable disease, by diagnosing it using the simple Pap-smear test and treating the cervical intra-epithelial pre-cancer lesions. These lesions show a prolonged biological behaviour starting from mild dysplastic changes to invasive cancer [3]. The sensitivity of detection of high grade squamous intraepithelial lesion (HSIL) using Pap-smear is 70-80\% [4]. However, considering the cost towards Pap-smear, implementing organised cytology-based screening programmes in India, is very difficult and not costeffective [5].In Trivandrum, South India, cervix uteri cancer incidence rates are low (9 per 100,000 women) [6] and hence organised screening programme are not costeffective. One possibility to detect this disease in early stage may be when women report to hospitals with symptoms like pain, vaginal discharge, lower abdominal pain, inter-menstrual bleed, post coital bleed etc., can routinely undergo Pap-smear test.

Facilities for routine Pap-smear examination of women attending the gynaecological outpatient departments of government hospitals is lacking in Kerala. In this context, a Pap-smear clinic has been started in the Women and Children (W \& C) Hospital, Trivandrum with technical assistance from the Regional Cancer Centre (RCC), Trivandrum since 2006. This present paper aims to assess the prevalence of cervical cytological abnormalities detected among women reported to the gynecology outpatient department of the W\&C hospital, and to assess the relationship between different socio-demographic/ reproductive factors and cervical cytological abnormalities using Pap-smear for 10,979 women reported in the W\&C hospital from 2010 to 2014.

\section{Materials and Methods}

W\&C Hospital (a tertiary care government hospital for women \& children), Thycaud, Trivandrum, South India, has been conducting a Pap-smear clinic twice a week with technical support from the RCC (cancer centre for treatment and research), Trivandrum, since 2006. The distance between these hospitals is $6 \mathrm{k} . \mathrm{m}$. Women attending the $\mathrm{W} \& \mathrm{C}$ hospital are mostly from lower socio economic status. The hospital provided adequate 


\section{International Journal of Science and Research (IJSR) \\ ISSN (Online): 2319-7064}

Index Copernicus Value (2015): 78.96 | Impact Factor (2015): 6.391

infrastructure and transported the samples to RCC. RCC was responsible for sample collection, consumables, processing, reporting and referral. A nominal amount was collected from the patient and the rest of the amount was provided the Trivandrum Corporation, Government of Kerala. Women attending W\&C hospital for any gynaecological problems were referred for routine twice a week Pap-smear clinic. Socio-demographic and reproductive factors were collected using a structured questionnaire after obtaining an informed consent.

The per speculum examination of the cervix and Papsmear (conventional) collection was done by a trained laboratory technician. The cervix of the patient was exposed adequately with a speculum. The squamocolumnar junction was scraped with the Ayre's spatula and cervix was scraped gently throughout its circumference and the specimen was spread into the glass slide and fixed in alcohol. The collected specimen was properly labelled with unique smear number. The same number was written in the card given to the woman whom she was requested to bring in the next clinic to obtain the Pap-smear report. The processing and reporting of the Pap-smear was done in the pathology division of RCC by a cytologist and the data were computerised. The reports were provided to the woman on the same day of the next week in the clinic and proper advises were given according to the Pap report.

Women with atypical squamous cells of undetermined significance (ASCUS) were advised strict follow-up after six months. Patients with low grade squamous intraepithelial lesions (LSIL) were advised colposcopy/strict follow-up after 3 months and colposcopy with or without LEEP excision as the case might be. High grade squamous intra-epithelial lesions (HSIL) were referred for colposcopy \& biopsy and LEEP excision or hysterectomy etc. Invasive cancers were referred for registration in RCC for treatment. The colposcopy and leep excision etc. were done by the gynaec oncologist in RCC. Women with an inflammatory smear were advised to repeat the Pap-smear after one year. An active follow-up system exists to make sure that all women who require any kind of further intervention.

Age, education, age at marriage, age at first delivery, number of pregnancy, nature of delivery and Per-speculum findings of cervix uteri were collected. Statistical significance between these variables and the cervical abnormalities were obtained using Chi-square test at 5\% level of significance. Using logistic regression model, odds ratio (OR) along with 95\% confidence interval (CI) was estimated to find the association of above sociodemographic and reproductive factors with Pap-smear diagnosis of HSIL/Ca and LSIL.

\section{Results}

In the present study, a total of 10,979 women who attended the gynaecology outpatient department of the W\&C hospital had been reported to the Pap-smear clinic during a period of 5 years. More than $95 \%$ of these women were from Trivandrum district. The major presenting complaints were abdominal pain (41.4\%), white discharge per vaginum (19\%) followed by inter-menstrual irregular bleeding (15\%), and low backache (13\%). HSIL/cancers were $113(1.03 \%)$. Among these, 58 cases were carcinomas of which 11 were adenocarcinomas. LSIL were $35(0.32 \%)$, ASCUS were $332(3.02 \%)$ and candidiasis $337(3.07 \%)$. Of the 332 ASCUS, 22 were atypical glandular cells of undetermined significance. Nearly $52 \%(n=5651)$ of women had inflammation. Using the active case-finding method, the cancer registry reported a total of 482 cervix uteri cancer patients from Trivandrum district (Table 1).

The age of 10,979 women ranged from 18 years to 89 years with mean age of 45.3 (SD: 9.3 )years. Nearly $81 \%$ of HSIL/ca, $81 \%$ of LSIL and $88.3 \%$ of ASCUS patients were in the age group of 35-64 years. The mean age at diagnosis of HSIL/Ca, LSIL and ASCUS were 51 (SD: 10.8 years), 44.3 (SD: 9.4 years) and 44.0 (SD: 7.7 years) years respectively and the same among women with normal diagnosis was 46.5 (SD: 9.7) years. Mean age at diagnosis of cervix uteri cancers $(n=482)$ in Trivandrum district was 60.4 (SD: 11.7) years (Table 1).

In the univariate analysis of HSIL/cancer vs. normal, it was observed that women with increased education, late age at marriage, late age first delivery, higher number of children $(\geq 2)$, normal cervix and delivery caesarian showed significantly low risk for developing HSIL/Ca. In the multivariate analysis, women with primary education and higher education had OR of 0.44 (CI: 0.18-1.07) and 0.20 (CI: 0.07-0.58) respectively for developing HISL/cancer compared to women with no education. Women with age at marriage 20-30 and $>30$ years had OR of 0.36 (CI: $0.20-0.63)$ and 0.23 (CI: 0.08-0.66) respectively for developing $\mathrm{HSIL} /$ cancer compared to women with age at marriage $<20$ years. Women with unhealthy and hypertrophied cervix had OR of 3.16 (CI: 1.80-5.54) and 2.44 (CI: 1.19-5.02) respectively for having $\mathrm{HISL} /$ cancer compared to women with normal cervix.

In the univariate analysis of ASCUS/LSIL vs. normal, it was observed that women with late age at marriage, normal cervix, women with lower number of pregnancies showed significantly low risk for developing LSIL. In the multivariate analysis, women with per-speculum finding of unhealthy or hypertrophied cervix have OR of 1.86 (CI: 1.38- 2.51) and 1.89 (CI: 1.30-2.74) than women with normal looking cervix to develop ASCUS/LSIL. Women with history of cesarean sections had OR of only 0.47 for developing LSIL/ASCUS (CI: 0.29-0.77) compared to normal delivery.

\section{Discussion}

In the present study, we observed HSIL/cancers in $1.1 \%$, LSIL in $0.03 \%$ and ASCUS in $3.0 \%$ among the 10,979 women with gynaecological problems reported to a tertiary care hospital in Trivandrum. Cervix uteri cancer incidence in Kerala was the lowest in India [6]. Lower proportion of squamous cell abnormalities in the present study could be due to the low incidence of this disease. Similar kind of a tertiary hospital-based study in Jaipur reported that ASCUS (4\%) was the most common epithelial cell 


\section{International Journal of Science and Research (IJSR) \\ ISSN (Online): 2319-7064}

Index Copernicus Value (2015): 78.96 | Impact Factor (2015): 6.391

abnormality followed by $1.6 \%$ LSIL and 1\% HSIL [7]. Low prevalence of this disease was reported in Japan and they reported that this was because of their cultural traditions and great concern regarding their health checkups and less likelihood of having multiple sexual partners [2]. In another hospital based study in Kuwait, reported that $1.6 \%$ had LSIL, and $0.4 \%$ had HSIL [8].As with the other studies, the percentage of carcinoma was lower than the percentage of dysplasia in Karnataka [9]. However, in a 35-year hospital-based cytology sample of 36,484 women in Lucknow, north India, reported $7.2 \%$ of squamous intra-epithelial lesions and $0.6 \%$ of carcinomas [10]. The difference in the prevalence of squamous abnormalities in the various hospital-based studies could be due to wide variation in referral bias.

As regards the age-distribution of the 10,979 women, nearly $81 \%$ of HSIL/ca, $81 \%$ of LSIL and $88 \%$ of ASCUS patients were in the age group of 35-64 years. The mean age at diagnosis of HSIL/Ca., LSIL and ASCUS were $51.0,44.2$ and 43.9 years respectively. Average age of women with cervix cancer in Trivandrum was 60 years [11]. Bhatia et al., [12] found mean age of 44 years in their study for pre-invasive lesions and found maximum cases of dysplasia in the age group of 31-40 years and carcinoma in the age group of 51-60 years. The difference in the age could be due to wide variation in selection criteria. In the present study, $76 \%$ of the cases were from the lower socioeconomic status. Kulkarni et al., [9] observed that $80 \%$ of cases of carcinoma cervix were from poor socio-economic status and from rural population.

In India, the age-standardized incidence rates of cervix uteri cancer have ranged from 6.1 to 30 per 100,000 women in different regions of India [6]. Although control of cervical cancer by early detection and treatment remains a priority of the National Cancer Control Programme of India, organized cytology screening programmes are definitely lacking due to the technical and financial constraints to organize cytology screening. Well organized comprehensive population based screening programme for cervical cancer have been carried out in a few areas in Kerala, Tamil Nadu and Maharashtra in India using visual screening methods with the support of the International Agency for Research on Cancer [13]. The major drawback of visual tests is its lower specificity which means large number of women may receive unnecessary treatment or additional investigations. Even though low resource country cannot afford cytology based screening tests, it is established that this is single test which had better sensitivity, specificity and predictive value. Data from the present hospital-based study was able to detect the efficiency of the Pap-smear screening programme in a clinic set-up. Hence Pap-smear clinics among high risk women may be a suitable strategy to detect this disease in early/pre-invasive stages in low income countries.

The major presenting complaints were abdominal pain, white discharge per vaginum followed by inter-menstrual irregular bleeding, and low backachein the present study. The major presenting complaint was white discharge per vagina $(26.8 \%)$ in the study of Bhatia et al. [12]. Majority of the patients complained white discharge per vagina
$(35.14 \%)$, the other symptoms were post-menopausal bleeding in $24.28 \%$ and irregular bleeding in $25.14 \%$ (Kulkarni et al., 2013).

In the present analysis of HSIL/Ca. vs. normal, it was observed that women with increased education, late age at marriage, normal cervix and delivery caesarian showed significantly low risk for developing HSIL/Ca. and the analysis of ASCUS/LSIL vs. normal, it was observed that women with late age at marriage, normal cervix, women with lower number of pregnancies showed significantly low risk for developing LSIL. Studies have shown that more number of pregnancies is associated with high risk of development of cervical neoplasia including cervical cancer which is attributed to the role of Human Papilloma Virus infection [14].

In conclusion, cervical cancer is one of the most common malignancies among women in India. Pap smear is a simple, cheap, safe and practical as a diagnostic tool for early detection of cervical cancer in high risk population, so it should be established as a routine diagnostic procedure in hospitals. Pap-smear clinics would help to detect women in pre-malignant conditions and also has a greater role in diagnosis of inflammatory lesions. In India, arrangements should be made for hospital based Papsmear clinics for all women attending hospital with gynaecologic complaints.

\section{Acknowledgement}

Trivandrum Corporation is greatly acknowledged for their financial support. Gynaecologists in Women\& Children hospital for patient referral, Ragini $\mathrm{K}$ for sample collection and Nanda KL for data collection and entry are also acknowledged.

\section{References}

[1] Ferlay J, Soerjomataram I, Dikshit R, et al. Cancer incidence and mortality worldwide: sources, methods and major patterns in GLOBOCAN 2012, International Journal of Cancer, 2014.

[2] Katanoda K, Atsuda T, Matsuda A, et al. An updated report of the trends in cancer incidence and mortality in Japan, Japanese Journal of Clinical Oncology, 2013; 43:492-507.

[3] Luthra UK, Prabhakar AK, Seth P, et al. Natural history of precancerous and early cancerous lesions of the uterine cervix, ActaCytologica, 1987; 31(3): 22634.

[4] Karimi-Zarchi M,Peighmbari F, Karimi N, Rohi M, Chiti Z. A comparison of 3 ways of conventional Papsmear, liquid-based cytology and colposcopy vs cervical biopsy for early diagnosis of pre-malignant lesions or cervical cancer in women with abnormal conventional Pap-test. International Journal of Biomedical Science, 2013; 9(4): 205-10.

[5] Aswathy S, Quereshi MA, Kurian B, and Leelamoni K. Cervical cancer screening: Current knowledge \& practice among women in a rural population of Kerala, India, Indian Journal of Medical Research, 2012; 136(2): 205-210.

\section{Volume 6 Issue 1, January 2017




\section{International Journal of Science and Research (IJSR) \\ ISSN (Online): 2319-7064 \\ Index Copernicus Value (2015): 78.96 | Impact Factor (2015): 6.391}

[6] NCRP (National Cancer Registry Programme). Three year report of the Population Based Cancer Registries 2012-2014: Report of 27 PBCRs. Indian Council of Medical Research, Bangalore, India, 2016.

[7] Rathore SB, Atal R. Study of cervical Pap smears in a tertiary hospital, International Journal of Science and Research, 2016; 5(5), ISSN (Online): 2071-2074.

[8] Kapila K, George SS, Al-Shaheen A, et al.Changing spectrum of squamous cell abnormalities observed on Papanicolaou smears in Mubarak Al-Kabeer Hospital, Kuwait, over a 13-year period, Medical Principles and Practices, 2006; 15(4): 253-259.

[9] Kulkarni PR, Rani H, Vimalambike MG, Ravishankar S. Opportunistic Screening for Cervical Cancer in a Tertiary Hospital in Karnataka, India. Asian Pac J Cancer Prev, 2013; 14 (9), 5101-5105.

[10] Misra JS, Srivastava S, Singh U, Srivastava AN.Riskfactors and strategies for control of carcinoma cervix in India: Hospital based cytological screening experience of 35 years, Indian Journal of Cancer, 2009; 46(2): 155-159.
[11]PBCR (Population based cancer registry), Thiruvananthapuram report (2012-2014), Published by Regional Cancer Centre, Thiruvananthapuram, 2017.

[12] Bhatia R, Goel S, Pal S, Sareen AR. Down staging of carcinoma cervix by Pap smear in high risk women. Obs.andGynae, 2001; 4, 29-36.

[13] Sankaranarayanan R, Nene BM, Dinshaw KA, et al. A cluster randomized controlled trial of visual, cytology and human papillomavirus screening for cancer of the cervix in rural India, International Journal of Cancer. 2005; 116: 617-623.

[14] Muñoz N, Franceschi S, Bosetti C, et al. International Agency for Research on Cancer. Multi centric cervical cancer study group. Role of parity and human papillomavirus in cervical cancer: the IARC multicentric case-control study, Lancet. 2002 Mar 30; 359 (9312):1093-101.

Table 1: Age distribution of Pap-smear results of 10,979 women attended in W\&C Hospital, Trivandrum (2009-14) and Cervical cancer cases reported in PBCR*, Trivandrum, 2012

\begin{tabular}{|c|c|c|c|c|c|c|c|}
\hline $\begin{array}{c}\text { Age } \\
(\text { years })\end{array}$ & $\begin{array}{c}\text { PBCR, } \\
(\mathrm{n}=482) \\
\#(\%)\end{array}$ & $\begin{array}{c}\text { Ca/HSIL* } \\
(\mathrm{n}=113) \\
\#(\%)\end{array}$ & $\begin{array}{c}\text { LSIL* } \\
(\mathrm{n}=35) \\
\#(\%)\end{array}$ & $\begin{array}{c}\text { Atypia } \\
(\mathrm{n}=332) \\
\#(\%)\end{array}$ & $\begin{array}{c}\text { Candidais } \\
(\mathrm{n}=337) \\
\#(\%)\end{array}$ & $\begin{array}{c}\text { Inflamm. } \\
(\mathrm{n}=5651) \\
\#(\%)\end{array}$ & $\begin{array}{c}\text { Normal } \\
(\mathrm{n}=4511) \\
\#(\%)\end{array}$ \\
\hline$<35$ & $2(0.4)$ & $4(3.5)$ & $6(17.1)$ & $34(10.25)$ & $34(10.1)$ & $636(11.3)$ & $367(8.1)$ \\
\hline $35-44$ & $37(7.7)$ & $31(27.4)$ & $10(28.6)$ & $134(40.4)$ & $151(44.8)$ & $2374(42.1)$ & $1662(36.9)$ \\
\hline $45-54$ & $114(23.7)$ & $40(35.4)$ & $16(45.7)$ & $138(41.6)$ & $125(37.1)$ & $1995(35.3)$ & $1662(36.9)$ \\
\hline $55-64$ & $157(32.6)$ & $20(17.7)$ & $2(5.75)$ & $21(6.3)$ & $22(6.5)$ & $478(8.5)$ & $544(12.1)$ \\
\hline $65+$ & $172(35.7)$ & $4(3.5)$ & $1(2.9)$ & $5(1.5)$ & $5(1.5)$ & $161(2.9)$ & $274(6.1)$ \\
\hline Mean & 60.39 & 50.91 & 44.26 & 43.97 & 43.77 & 44.31 & 46.52 \\
\hline SD & 11.72 & 10.75 & 9.39 & 7.743 & 7.94 & 8.93 & 9.72 \\
\hline
\end{tabular}

*PBCR: Population-based cancer registry; HSIL- High-grade Squamous Intraepithelial Lesion; LSIL- Low-grade Squamous Intraepithelial Lesion

Table 2: Odds ratio (95\% CI) for Squamous cell abnormalities according to reproductive factors: Multivariate logistic regression analysis

\begin{tabular}{|c|c|c|c|c|c|c|}
\hline \multirow{2}{*}{ Factors } & \multicolumn{3}{|c|}{ HSIL $^{1}$ / Cancer vs. normal } & \multicolumn{3}{|c|}{ LSIL $^{2}$ vs. normal } \\
\hline & OR & $95 \%$ CI & p-value & OR & $95 \%$ CI & p-value \\
\hline \multicolumn{7}{|c|}{$\begin{array}{l}\text { Education level } \\
\end{array}$} \\
\hline Illiterate & 1 & & & 1 & & \\
\hline Primary & 0.436 & $0.178-1.067$ & 0.069 & 0.690 & $0.367-1.269$ & 0.249 \\
\hline Secondary\& Above & 0.200 & $0.070-0.575$ & 0.003 & 0.499 & $0.799-0.417$ & 1.531 \\
\hline \multicolumn{7}{|c|}{ Age at marriage } \\
\hline$<=20$ years & 1 & & & 1 & & \\
\hline 21-30 years & 0.358 & 0.202.-0.634 & 0.001 & 0.927 & $0.701-1.224$ & 0.592 \\
\hline$>30$ years & 0.232 & $0.082-0.656$ & 0.006 & 0.859 & $0.580-1.270$ & 0.446 \\
\hline \multicolumn{7}{|c|}{ Per-speculum finding of Cervix } \\
\hline Normal Cervix & 1 & & & 1 & & \\
\hline Unhealthy Cervix & 3.161 & $1.803-5.542$ & 0.001 & 1.860 & $1.375-2.514$ & 0.001 \\
\hline Hypertrophied Cervix & 2.441 & 1.188-5.018 & 0.015 & 1.886 & 1.296-2.744 & 0.001 \\
\hline \multicolumn{7}{|c|}{ Type of delivery } \\
\hline Normal delivery & 1 & & & 1 & & \\
\hline Caesarean section & 0.318 & $0.076-1.332$ & 0.117 & 0.473 & $0.290-0.772$ & 0.003 \\
\hline
\end{tabular}

\section{HSIL-High-grade Squamous Intraepithelial Lesion; 2. LSIL-Low-grade Squamous Intraepithelial Lesion}

\section{Authors Profile}

Dr. Kalavathy M. C., Assistant Professor, Division of Cancer Epidemiology \& Biostatistics, Regional Cancer Centre, Trivandrum has more than 22 years of professional experience and has distinguished herself as an expert in the field of cervical and breast cancer prevention, Cervical cancer and HPV association, cancer awareness and also medical officer in the functioning of Cancer Registries. She had her basic medical degree followed by her Master's in Public Health. She started her career in cancer research as the medical officer of a population based programme on

\section{Volume 6 Issue 1, January 2017}




\section{International Journal of Science and Research (IJSR) \\ ISSN (Online): 2319-7064}

Index Copernicus Value (2015): 78.96 | Impact Factor (2015): 6.391

"Natural History of Human Papilloma Virus" in 1993. She also has experience of working as Coordinator of the Cancer Control Programme in women in the northern districts of Kannur, Wyanadu and Kasargod funded by UNFPA. She started the Trivandrum Corporation Cancer Control Programme in 2003 and the programme is being continued till date. She has also the coordinator for the Trivandrum District Cancer Controrl Programme under the auspice of Trivandrum Jilla Panchayath and this programme was unique in involving the grass root level health workers called ASHA workers in cancer control. She took initiative in setting up a regular Pap-smear clinic in the apex Women and Children Hospital, Trivandrum, South India which is being conducted uninterrupted till date and screened more than 19,000 women in this programme. She has 18 publications in the field of Breast and Cervical cancer prevention and tobacco related cancers and mainly these are papers presented in national and international conferences.

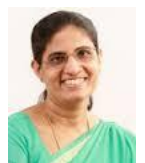

Dr. Aleyamma Mathew, Professor \& Head, division of Cancer Epidemiology \& Biostatistics, Regional Cancer Centre, Trivandrum has more than 25 years of professional experience and has distinguished herself as a scientist, teacher and an administrator of high repute. She has a brilliant academic record, First Rank holder in M.Sc. (Statistics), Ph.D. in Cancer Epidemiology from the University of Tampere, Finland and Ph.D. in Statistics from Mahatma Gandhi University, Kottayam. She is widely recognized for her work in the field of cancer epidemiology and bio-statistics. Dr. Mathew's investigations in the area of breast, cervix uteri, colorectum and stomach cancers have paved way for successful intervention strategies for cancer control and prevention. The role of life-style and reproductive factors in the etiology of breast cancer has been well investigated by her. She is a recipient of FAMS by the National Academy of Medical Sciences (NAMS) and the prestigious fellowship from National Institute of Health (NIH), USA, for carrying out postdoctoral work. In the US, she worked on diet and cancer and has developed large-scale epidemiological studies in the country which are being funded by NIH. She has been conducting a large number of collaborative projects during the past 15 years and has expanded the academic and research activities of the division. She has conducted several training courses in the field of Cancer Epidemiology \& Bio-statistics. She has published 94 papers in indexed journals till date. She is an author of several chapters in the books being published from India and abroad. She has received several awards for her contributions and recently received Achantha Lakshmipathi oration by the NAMS (2016).

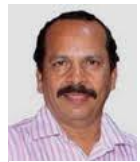

Dr. K. Sujathan had Post-doctoral programme at $\mathrm{RCC}$ after $\mathrm{PhD}$ at Annamalai University, Tamil Nadu and currently Associate Professor at the Division of Cancer Research of the Regional Cancer Centre, Trivandrum, Kerala. Dr. Sujathan is a recognized Research guide and $\mathrm{PhD}$ examiner in several Universities in India and external faculty for the integrated M.Sc programme of Kerala Agriculture University. Several research programmes have been undertaken by him and currently Principal Investigator in four ongoing research projects funded by different national and international agencies. Received 4 National awards for his research works. $5 \mathrm{PhD}$ students are currently working under his supervision and $2 \mathrm{PhDs}$ have been awarded. One Patent application has been filed: (Indian Complete Patent Appl.No. 4098/CHE/2015: "A Method and system for automated screening of cervical cancer") and another one submitted (Ref. No.: 0080NF2016: "Label free detection of precancerous lesions of cervix using Surface Enhanced Raman Spectroscopy and a Process for the Preparation thereof'). Dr. Sujathan has published 37 journal papers and 32 conference papers and has edited one handbook of Cytopathology.

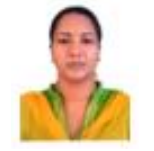

Saritha V.N. is currently working as a Senior Research Fellow, Division of Cancer Research, Regional Cancer Centre, Trivandrum and doing Ph.D (MS University Thirunelveli) in cancer biology and her field of interest is Proteomic analysis of malignant and premalignant lesions of the uterine cervix and cancer Cytopathology. She is a post graduate in life science and has undergone cytotechnologist training course at Regional Cancer Centre, Trivandrum. She has ten years experience in cytology field and has publication in an International Journal. She has presented six research papers in various national and international conferences.

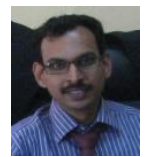

Dr. Jagathnath Krishna K. M., Assistant Professor in Biostatistics, division of Cancer Epidemiology \& Bio-statistics, Regional Cancer Centre, Trivandrum has six and half years of research experience after obtaining his Ph.D. in Statistics from Cochin University of Science and Technology, Cochin. He worked in different capacity in diverse field which includes Lecturer at Amrita Institute of Medical Sciences, Kochi and as Scientist \& Assistant Professor (Academy of Scientific and Innovative Research (AcSIR)) at CSIR- Central Leather Research Institute, Adyar, Chennai. He was awarded two Post-Doctoral fellowships; National Board of Higher Mathematics (NBHM), Department of Atomic Energy, Govt. of India during 2010 and Dr. D. S. Kothari Postdoctoral Research Fellowship (UGC, Govt. of India) during 2011. He has 20 publications and one software copyright to his credit. He also received several other awards, recognitions and an appreciation within a short academic career. He has delivered more than 10 invited lectures. He is reviewer for two of international journals. He also involved in collaborative projects both in national and international levels and completed one national project as principal investigator and completed two international projects as team member. His area of research includes; Reliability Analysis, Distribution Modeling, Survival Analysis, Trend Analysis and Statistical Data Analysis \& Modeling.

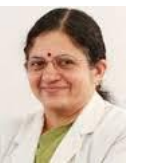

Dr. Jayasree K., Professor and Head, Division of Pathology, Regional Cancer Centre, Trivandrum obtained her MD (Pathology) from Calicut Medical College. She has more than 25 years of experience in Pathology and 20 years of experience in Oncopathology and Cytology. She is examiner for National Cytotechnology and Cytotechnician 


\section{International Journal of Science and Research (IJSR) \\ ISSN (Online): 2319-7064}

Index Copernicus Value (2015): 78.96 | Impact Factor (2015): 6.391

examinations conducted by IAC and faculty for various CMEs -International, National and Regional CMEs. She has been awarded ICRETT Fellowship (UICC) 2004 for short term training in Oncopathology with special reference to Bone and Soft Tissue tumours at Mayo Clinic, Rochester, Minnesota, USA. She is also recipient of Fellow of Indian College of Pathologists-2013. She has completed several National and International projects as Principal Investigators and currently she is holding three external funded projects. She has many publications in National and International journals and book chapters to her credit. She also attended several International training programs. 